\title{
Preoperative markers of Cushing's disease remission after transsphenoidal endoscopic surgery
}

Gussaova N.V., Tsoy U.A., Cherebillo V.Yu., Savello A.V., Paltsev A.A., Solntsev V.N., Ryazanov P.A., Mitrofanova L.B., Grineva E.N. Federal Almazov North-West Medical Research Centre, Saint-Petersburg, Russian Federation

\section{INTRODUCTION}

Transsphenoidal endoscopic surgery (TSS) is the first-line treatment for Cushing's disease (CD).

However, persistence and recurrence of hypercortisolism after TSS considered important problem. In this case search for $C D$ remission predictors is actual.

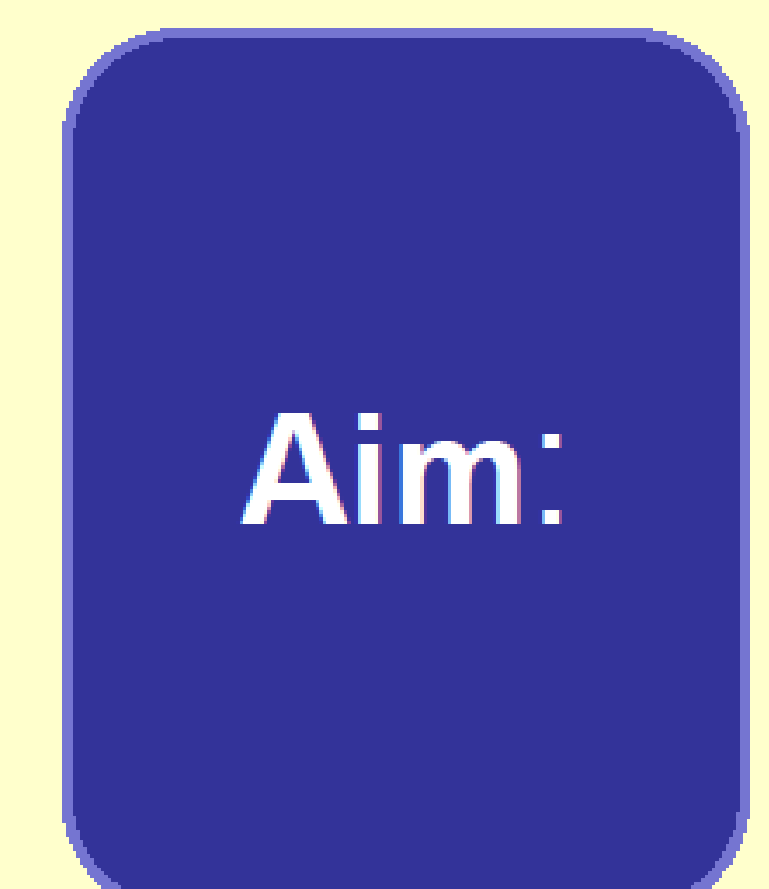

To investigate the role of preoperative oral high-dose dexamethasone suppression test (HDDST)

- To study the role of preoperative pituitary MRI in the prognosis of $C D$ remission after TSS.

\section{METHODS}

59 patients with Cushing's disease ( 9 men, 50 women, mean age 40 years (15-72) underwent TSS were included.

$\checkmark$ Before the TSS HDDST and pituitary MRI were performed in all cases (MRI adenoma $\geq 10 \mathrm{~mm}$ - macroadenoma, $<10 \mathrm{~mm}-$ microadenoma).

$\checkmark$ Postoperative examination was done one year after surgery.

$\checkmark$ Remission criteria were: secondary adrenal insufficiency (the need for glucocorticoid replacement) or combination of normal midnight ACTH and serum cortisol levels, normal 24 hour urine free cortisol (UFC) excretion and serum cortisol suppression less than $50 \mathrm{nmol} / \mathrm{l}$ in 1-mg dexamethasone test.

$\checkmark$ The optimal threshold value of serum cortisol suppression in the HDDST for prediction of CD remission after TSS was calculated by ROC-analysis.

\section{RESULTS}

$\checkmark$ One year after surgery CD remission was confirmed in 39 patients, whereas in 20 patients hypercortisolism persisted (Fig.1, table 1).

$\checkmark$ ROC-analysis identified $72 \%$ as the best cut off value of serum cortisol suppression in the HDDST for prediction of CD remission after TSS (Fig. 2, 3).

$\checkmark$ Test's sensitivity and specificity were $82 \%$ and $84 \%$, respectively. The probability of wrong prediction was $17 \%(p=0,0001)$.

$\checkmark$ In our study, there was no significant difference in the remission rate in patients with micro- and macroadenomas $(x 2=0,03, p=0,87)$ (Table 2).

Table 1. Patients characteristics $(n=59)$

\begin{tabular}{|l|l|l|}
\hline & Remission $\mathbf{( n = 3 9 )}$ & Non-remission $(\mathbf{n = 2 0})$ \\
\hline Age, years & $40,9(21-72)$ & $37,5(15-63)$ \\
\hline Male/female (n) & $6 / 33$ & $3 / 17$ \\
\hline Serum cortisol, nmol/l (171-536) & $697(224-1518)$ & $842,9(514-1750)$ \\
\hline 24 UFC, nmol/24 h (11.8 - 485.6) & $988,4(138-6406)$ & $2237,2(156,6-8740)$ \\
\hline ACTH, pg/mI (7,2-63,3) & $74,17(15,1-200)$ & $70,23(19,64-241,9)$ \\
\hline MRI micro/macroadenoma & $32 / 7$ & $16 / 4$ \\
\hline
\end{tabular}

\section{Fig. 1 The outcomes of TSS 12 month after} treatment

Pathological $(n=49)$ and clinical $(n=10)$

confirmation of CD after TSS $(n=59)$

$$
\begin{gathered}
\text { Follow-up } 12 \text { month } \\
\qquad \begin{array}{c}
\text { Remission } \\
(\mathrm{n}=39)
\end{array} \\
\begin{array}{c}
\text { Non-remission } \\
(\mathrm{n}=20)
\end{array}
\end{gathered}
$$

Fig.2 The optimal threshold value of serum cortisol suppression in the HDDST for prediction of CD remission after TSS (ROC-curve)

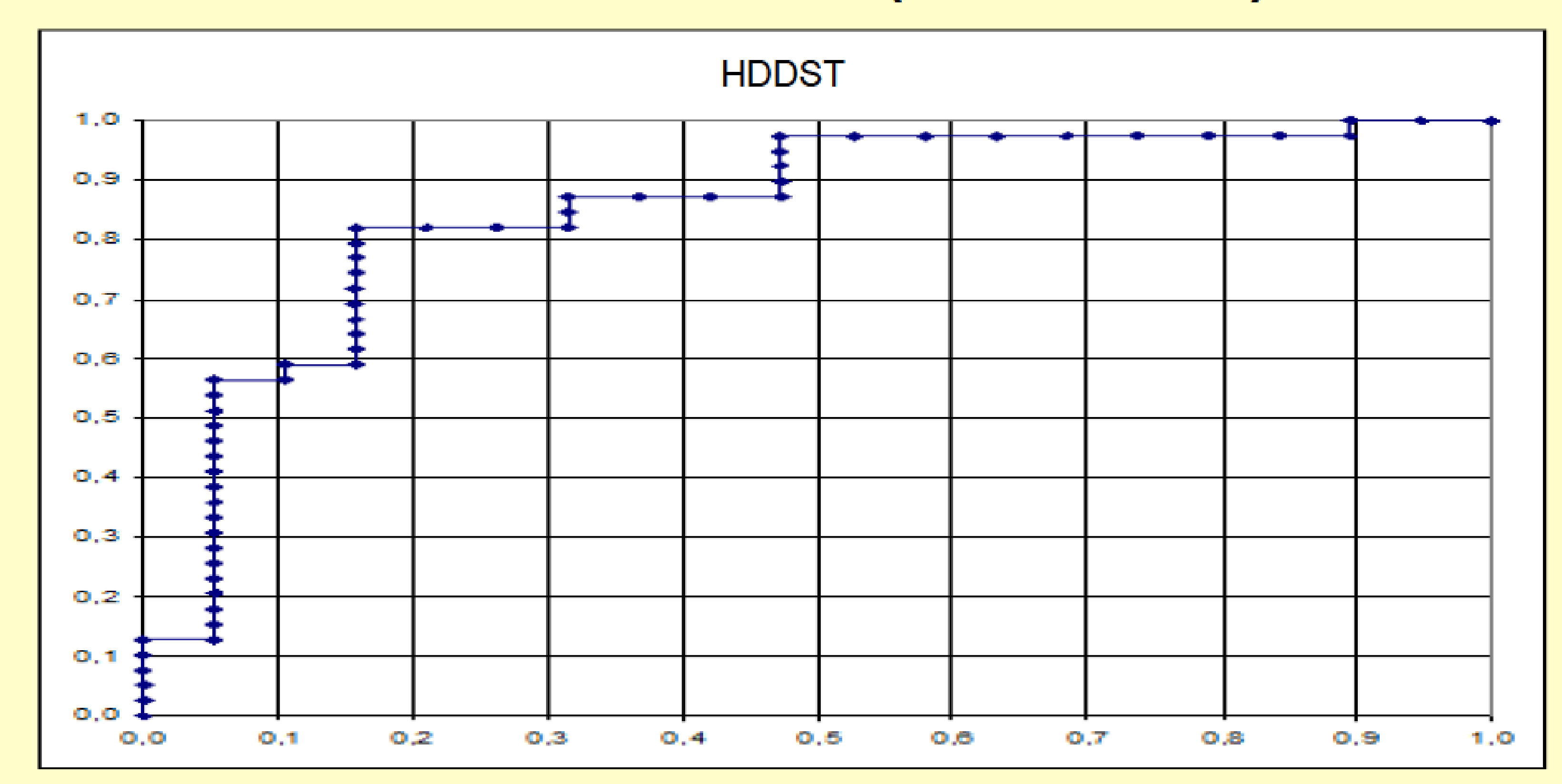

Fig.3: The number of remission and non-remission patients in groups with cortisol suppression $\geq 72 \%$ and $<72 \%$ in the HDDT

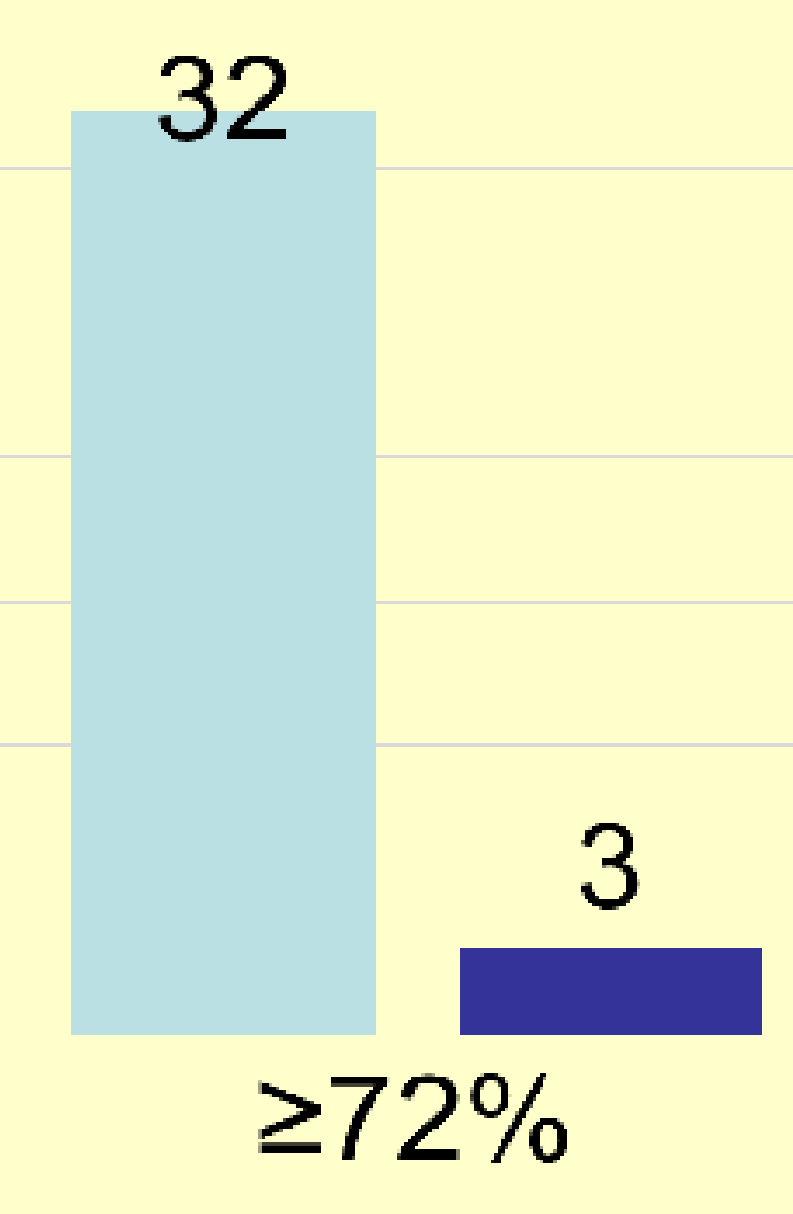

remission

non-remission
32

3

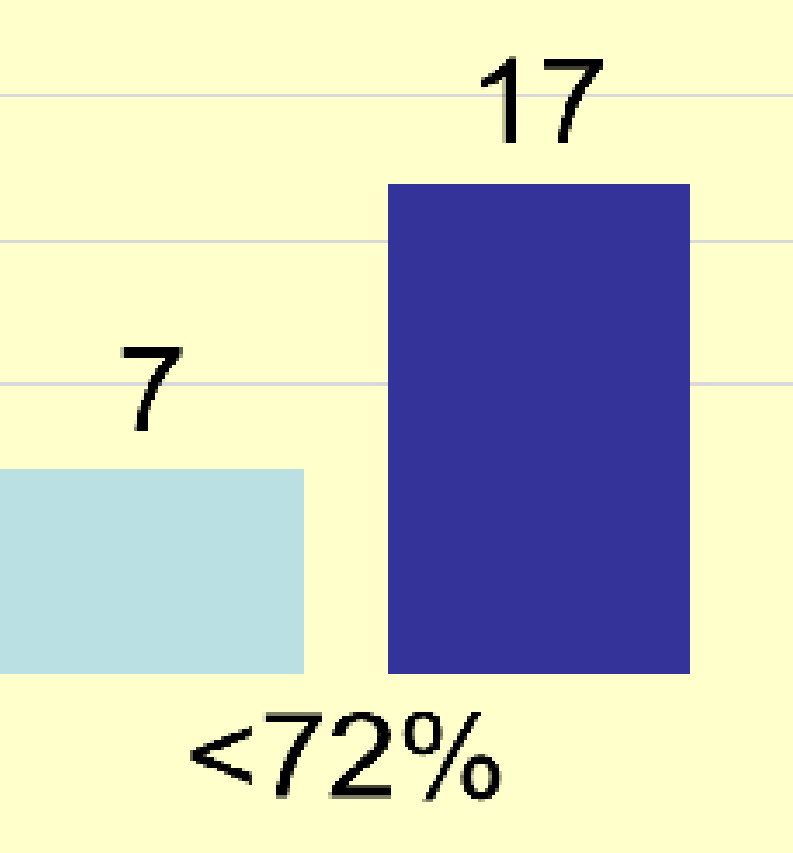

7

17
Table 2. Remission and non-remission rate after TSS in patients with micro- and macroademomas

\begin{tabular}{|l|l|l|}
\hline & $\begin{array}{l}\text { Microadenoma } \\
(n=48)\end{array}$ & $\begin{array}{l}\text { Macroadenoma } \\
(n=11)\end{array}$ \\
\hline Remission & $\begin{array}{l}67 \% \\
(n=32)\end{array}$ & $\begin{array}{l}64 \% \\
(n=7)\end{array}$ \\
\hline Non-Remission & $\begin{array}{l}33 \% \\
(n=16)\end{array}$ & $\begin{array}{l}36 \% \\
(n=4)\end{array}$ \\
\hline
\end{tabular}

\section{CONCLUSIONS}

According to our data serum cortisol suppression more than $72 \%$ in HDDST may be used as a one of prognostic criterion for CD remission after TSS. There was not correlation between MRI adenoma size and the outcomes of TSS. 